\title{
PENDIDIKAN ISLAM ANAK USIA DINI DALAM PERSPEKTIF NEUROSAINS: ROBOTIK AKADEMIK DAN SAINTIFIK
}

\author{
Suyadi \\ Universitas Ahmad Dahlan Yogyakarta, Indonesia \\ suyadi@fai.uad.ac.id
}

\begin{abstract}
EARLY CHILDHOOD ISLAMIC EDUCATION IN NEUROSAINS PERSPECTIVE: ROBOTIC, ACADEMIC AND SCIENTIFIC; There are political, academic, and theological dilemmas in Early Childhood Islamic Education or Pendidikan Anak Usia Dini (PIAUD) in Yogyakarta. PAUD is required to hold reading, writing and numeracy learning, including Al-Qur'an Reading, but on the other hand, PAUD Directorate forbids it. The purpose of this study is to describe the types of early childhood learning in neuroscience studies. This research was carried out throughout 2017 involving nine PIAUD institutions. The research approach is qualitative. Data collection techniques were in the form of interviews, observation and documentation. The collected data were analyzed descriptively, interpretatively, and comparatively. The results showed that PIAUD in Yogyakarta can be categorized into three. First, robotics PIAUD, namely PIAUD which risks damaging the child's brain. Secondly, academic PIAUD, namely PIAUD which is at risk of giving limitation to the child's brain. Third is scientific PIAUD. It is PIAUD which is oriented in optimizing the potential of the brain.
\end{abstract}

Keywords: Early Childhood Islamic Education, Neuroscience; robotic, academic, and scientific PAUD. 


\begin{abstract}
Abstrak
Pendidikan Islam Anak Usia Dini (PIAUD) di Yogyakarta dihadapkan pada dilema politis, akademis, dan teologis. Di satu sisi PIAUD dituntut menyelenggarkan pembelajaran membaca, menulis dan berhitung, termasuk Baca Tulis Al-Qur'an, namun di sisi lain Direktorat Jenderal PAUD melarangnya. Tujuan penelitian ini adalah mendiskripsikan tipetipe pembelajaran anak usia dini dalam kajian neurosains. Penelitian ini dilakukan sepanjang tahun 2017 dengan melibatkan sembilan lembaga PIAUD. Pendekatan penelitian ini adalah kualitatif. Teknik pengumpulan data berupa wawancara, observasi dan dokumentasi. Data-data yang terkumpul dianalisis secara deskriptif, interpretatif, dan komparatif. Hasil penelitian menunjukkan bahwa PIAUD di Yogyakarta dapat dipetakkan menjadi tiga. Pertama, PIAUD robotik, yaitu PIAUD yang beresiko merusak otak anak. Kedua, PIAUD akademik, yaitu PIAUD yang beresiko membonsai otak anak. Ketiga, PIAUD saintifik, yaitu PIAUD yang berorientasi pada optimalisasi potensi otak.
\end{abstract}

Kata Kunci: PIAUD, Neurosains, Pembelajaran Membaca Menulis dan Berhitung; PAUD Robotik, Akademik dan Saintifik.

\title{
A. Pendahuluan
}

Hubungan antara orang tua dan masyarakat dengan lembaga pendidikan, khususnya Pendidikan Anak Usia Dini (PAUD) (Suyadi dan Maulidya Ulfa 2013) yang menurut Ki Hadjar Dewantoro seharusnya sinergis (tri pusat pendidikan) (Dewantara 1962: 3) kini mengalami disharmonis. Di satu sisi masyarakat atau orangtua memiliki tuntutan ganda selain anak harus memiliki karakter atau akhlak yang baik (Prasekolah and Zulaikhah n.d., 2013: 355), (Ali 2015: 190) anak juga harus kemampuan membaca, menulis dan berhitung (calistung). Tetapi di sisi lain, lembaga PAUD dilarang oleh Direktorat Jenderal Pendidikan Anak Usia Dini (Dirjen PAUD) tidak boleh menyelengarakan pembelajaran calistung (Nasional, Jenderal, and Menengah 2009). Jika PAUD mengikuti tuntutan masyarakat berarti PAUD tersebut harus melanggar larangan Dirjen PAUD sekaligus melakukan mal praktik pembelajaran yang berpotensi merusak otak anak. Namun jika PAUD mengindahkan larangan Dirjen PAUD untuk tidak menyelenggarakan pembelajaran calistung, maka PAUD tersebut akan ditinggalkan masyarakat, sepi 
peminat, bahkan dimungkinkan tutup. Dalam situasi yang serba dilematis tersebut, semua lembaga PAUD melakukan "rekayasa" agar tidak melanggar larangan dirjen PAUD, tetapi dapat memenuhi tuntutan orangtua dan masyarakat sehingga anak-anak mereka bisa calistung sejak dini (Ismatul Khasanah 2013: 14), (Stys and Brown 2013). Di Pekalongan, Jawa Tengah Misalnya, TK Wiradesa secara formal tidak menyelenggarakan pembelajaran calistung, tetapi secara informal para guru di dalamnya membuka les tambahan calistung di luar jam pembelajaran (Istiyani 2013: 3-5); TK N 1 Sleman Yogyakarta meskipun tidak mengajarkan calistung secara langsung, namun semua permainan dan atau kegiatannya lainnya diorientasikan pada penguasaan calistung; Fustrack Funschol Yogyakarta mengajarkan calistung melalui permainan-perainan yang menyenangkan sehingga anak tidak merasa sedang belajar calistung. Di tengah-tengah masyarakat sendiri Lomo, Depok, misalnya telah berkembang program parenting tetapi isinya penyuluhan agar orang tua mengajarkan calistung kepada anaknya (Widyastuti 2018: 6667). Hingga saat ini, kontroversi pembelajaran calistung pada jejang PAUD terus berlangsung, meskipun telah dikaji dalam berbagai perspektif, terutama psikologi kognitif dan neurosains.

Meskipun di Indoneia kontroversi calistung baru hangat diperbicangkan akhir-akhir ini, tetapi di Amerika isu tersebut telah dimulai sejak 1988 ketika Connie Juel melakukan penelitian tentang membaca dan menulis bagi anak-anak sampai kelas empat (Juel 1988: 437). Wajar jika saat ini Amerika telah membuat kebijakan nasional untuk mencanangkan gerakan calistung, terutama pembelajaran matematika sejak dini (Committee on Early Childhood Mathematics 2009: viii). Rendahnya kualitas pembelajaran matematika selama berabad-abad disebabkan karena tidak adanya dasar pembelajaran matematika sejak awal, sehingga merugikan masa depan anak, baik secara ekonomi maupun pengembangan ilmu pengetahuan itu sendiri (Ismatul Khasanah 2013). Pendidikan matematika telah menjadi bagian penting dalam kurikulum pendidikan anak usia dini (balitas, pra sekolah dan sekolah dasar) di seluruh dunia. Landasan memahami konsep matematika yang berhubungan dengan akal dan angka harus dimulai dari awal kehidupan sebagai benih kehidupan di masa mendatang (Suparni 2016: 57). Teori Vigotsky juga telah dimanfaatkan untuk pembelajaran matematika secara kolaboratif bagi 
anak usia dini (Cicconi 2014: 57). Bahkan beberapa peneliti Amerika telah spesifik mengembangkan pembelajaran ini khusus bagi anak difabel (Fischer 2009). Penelitian terbaru tentang calistung sudah sampai pada pembuktian bahwa materi akademik pada pendidikan anak usia dini memberi pengaruh kuat bagi pendidikan selanjutnya (Manfra et al. 2017: 528). Bahkan di India, sudah mencanangkan kebijakan kualitas perawatan anak untuk menyiapkan generasi unggul (Reetu 2017: 41).

Penelitian ini mengkaji tentang ragam pembelajaran calitung dalam perspektif neurosains di berbagai lembaga PAUD/PIAUD di Yogyakarta secara tipologis. Pemetaan ini penting dilakukan dalam rangka merumuskan model pembelajaran anak usia dini (termasuk calistung) terbaik, yang sesuai dengan perkembangan dan karakteristik cara kerja otak (Dundar and Ayvaz 2016). Mengingat pembelajaran menyangkut banyak aspek, maka pemetaan ini diperluas tidak hanya obyek pembelajaran itu sendiri, melainkan juga subyeknya yang mencakup guru, siswa, materi, strategi dan evaluasi. Berdasarkan pemetaan tersebut, masyarakat dapat menentukan pilihan PAUD terbaik bagi anak-anak mereka. Bagi lembaga PAUD sendiri dapat memperbaiki proses pembelajaran menyesuaikan temuan-temuan dalam penelitian ini, yakni sesuai perkembangan dan karakteristik cara kerja otak.

Penggunaan perspektif neurosains diperlukan mengingat neurosains saat ini telah menjadi dasar bagi praktik pembelajaran anak usia dini (George S. Morrison 2012: 44) (Morrison 2007: 10). Dalam kajian neurosains, stimulasi edukatif yang bersifat abstrak seperti calistung, tidak dapat direspons anak usia dini karena perkembangan otaknya masih pada tahap pra operasional sehingga beresiko "merusak" otak. Tetapi, memberikan stimulasi yang sifatnya empirik dengan muatan akademik yang terlalu tinggi, termasuk calistung, juga dapat beresiko "membonsai" otak anak. Hanya stimulasi yang benar-benar sesuai dengan perkembangan otak anak yang dapat mengoptimalkan potensi otak anak.

\section{B. Pembahasan}

Pemetaan atau tipologi PAUD dalam penelitian ini diukur dari kesesuaiannya dengan hasil-hasil penelitian tentang otak atau 
neurosains, terutama neurosains pendidikan Islam (Pasiak 2016: 132). Menurut teori pembelajaran neurosains, kortek prefrontal (otak bagian luar yang berfungsi untuk berpikir kritis dan kreatif) pada otak anak usia dini belum berkembang maksimal sehingga belum bisa merespons stimulus yang sifatnya abstrak dan rasional, seperti calistung (Anderson-McNamee 2010). Karakteristik otak pada tahap ini baru bisa menerima stimulus yang sifatnya kongkrit dan empirik, seperti bermain (Nouri 2016). Berdasarkan penjelasan neurosains ini, PAUD yang memberikan stimulasi abstrak tidak sesuai dengan perkembangan otak anak sehingga berisiko merusak otak anak. Dalam hal ini, PAUD yang berpotensi merusak otak anak disebut sebagai PAUD Robotik. Disebut robotik karena praktik pembelajarannya seperti robot, tidak memakai otak, atau tidak mengacu pada cara kerja otak sebagaimana yang dijelaskan dalam ilmu otak (neurosains).

Mengingat jika PAUD hanya mengikuti teori pembelajaran neurosains sepenuhnya akan ditinggalkan masyarakat karena tidak membelajarkan calistung, maka sebagian besar melakukan rekayasa melalui bermain (bermain sambil belajar: calistung). Semua kegiatan dan atau permainan diberi muatan calistung agar anak mampu calistung. Dengan kata potensi otak anak yang luar biasa hanya digunakan untuk mempelajari calistung. Hal ini sama saja dengan pembonsaian atau pengkerdilan potensi otak. Dalam neurosains dijelaskan bahwa anak yang baru lahir mempunyai 100-200 miliyar neuron (Pasiak 2009: 91). Pada usia dua tahun perkembangan otaknya telah mencapai $75 \%$, pada usia 5 tahun perkembangan otaknya telah mencapai $90 \%$ dan pada 10 tahun perkembangan otaknya telah mencapai 99\% (Suyadi 2014: 35). Di atas usia ini, perkembangan otak anak semakin melambat sehingga untuk mencapai $100 \%$ perlu menunggu hingga usia 18 tahun. Oleh karena itu, PAUD yang mengorientsikan semua kegiatan hanya untuk pengembangan kompetensi akademik, seperti calistung dapat dikatakan sebagai PAUD yang beresiko membonsai potensi otak anak. Di katakan membonsai otak karena potensi otak yang luar biasa hanya digunakan untuk pengembangan satu bidang, yakni kompetensi akademik dengan indikator calistung. Dalam hal ini, PAUD yang berpotensi membonsai otak anak disebut sebagai PAUD akademik. Disebut PAUD akademik karena orientasi utamanya adalah pengembangan akademik semata. 
PAUD Robotik dan akademik jelas bukan tipe PAUD ideal. PAUD yang ideal adalah PAUD yang sesuai dengan teori-teori pembelajaran, khususnya neurosains. PAUD inilah yang mampu melakukan optimalisasi potensi otak anak. Dalam hal ini, PAUD yang berorientasi pada optimalisasi potensi otak anak disebut dengan istilah PAUD Saintifik. Disebut PAUD Saintifik karena praktik pembelajarannya selalu mengacu teori-teori di bidang neurosains. PAUD Saintifik tidak merekayasa pembelajaran calistung sehingga anak-anak tidak sadar sedang belajar calistung; mereka tidak belajar calistung namun di akhir kegiatan memiliki kompetensi akademik yang bagus. PAUD Saintifik memandang anak yang bisa calistung sejak dini belum tentu cerdas, demikian pula sebaliknya, anakanak yang belum bisa calistung sejak dini belum tentu tidak cerdas. Pasalnya, dalam neurosains konsep kecerdasan tidak diukur dari kopetensi calistung, nemun jauh lebih luas, yang mencakup IQ EQ SQ dan Multipe Intellegences.

Oleh karena itu, penelitian ini memetakkan tipologi PAUD berdasarkan teori neurosains menjadi tiga tipe, yakni PAUD Robotik, PAUD Akademik, dan PAUD Saintifik. Mengingat bahwa calistung pada jenjang PAUD melibatkan setidaknya lima komponen, yakni guru, anak didik, materi pembelajaran, strategi pembelajaran atau dan evaluasi pembelajaran (Suyadi dan Maulidya Ulfa 2013: 56), maka penelitian ini merinci ciri-ciri PAUD Robotik, Akademik dan Saintifik berdasarkan kelima komponen tersebut.

\section{PAUD Robotik}

Secara etimologi, kata "robot" diartikan sebagai alat berupa orang-orangan dan sejenisnya yang bisa bergerak (berbuat seperti manusia yang dikendalikan oleh mesin. Di samping itu, robot juga diartikan sebagai orang yang menurut saja terhadap perintah orang lain. Dalam kamus Bahasa Indonesia dicontohkan, "Pakailah otakmu, jangan seperti robot saja." Di dunia maya, istilah robot diartikan sebagai serangkaian perangkat elektronik yang dapat dikendalikan secara mekanis utuk membantu keperluan manusia. Secara terminologi, menurut Munif Chatib istilah robot dilawankan dengan sekolahnya manusia (Chatib 2009: 91). Menurutnya, sekolahnya robot adalah sekolah yang menggunakan sejumlah tes ketika masuk, 
ingin mencetak semua anak yang berlatar belakang berbeda menjadi berkemampuan sama, menerapkan sistem ranking kelas, membuat kategori-kategori tertentu dan lain sebagainya (Chatib 2012: 61). Dalam hal ini, Munif Chatib tidak membuat definisi operasional mengenai sekolahya robot yang dimaksud, melainkan sebatas menyebutkan beberapa ciri-cirinya. Sebagaimana dijelaskan di atas, bahwa secara umum, yang dimaksud PAUD Robotik di sini adalah PAUD yang beresiko merusak otak anak. Berikut ini penjelasan lebih detail mengenai ciri-ciri PAUD robotik ditinjau dari lima komponen pendidikan, yakni guru, anak didik, strategi, materi dan evaluasi.

\section{a. Guru Robotik; diktator kelas}

Guru pada PAUD robotik (guru robotik) adalah diktator kelas yang mengajar dengan segala otoritasnya. Meminjam istilah Freire, ia mengajar dengan cara menggurui, guru mengajar anak diajar, guru memberi tahu anak diberitahu, guru mengatur anak diatur, guru memerintah anak diperintah dan seterusnya (Freire 2008: 34). Guru robotik banyak mengeluarkan instruksi, perintah, dan larangan yang harus ditaati anak tanpa boleh dibantah. Pada situasi tertentu, jika terdapat anak yang tetap tidak bisa diam maka guru robotik akan memberi hukuman, seperti jewer (menarik telinga anak), slentik (memukul telinga anak dengan jari tengah), jiwit (semacam dicubit namun dengan kebencian), dan lain sebagainya (Hook and Farah 2013). Jika anak yang dikenai hukuman menangis, biasanya guru pendamping menarik anak tersebut ke luar kelas. Ibu Musyarifah mengatakan, "Masih banyak, bahkan lebih dari 70\% guru TK/RA yang mengajar menjadi penguasa kelas, dan dia senang jika anak menjadi diam dan penurut."

Guru robotik juga dicirikan dengan banyaknya memberi perintah dan larangan, sehingga anak benar-benar dikendalikan. Jika pedagogi ini dilihat dari kacamata neurosains, maka otak anak dalam situasi tegang dan takut-mencekam, sehingga tidak dapat berkembang. Lihat salah satu contoh situasi berikut ini: 


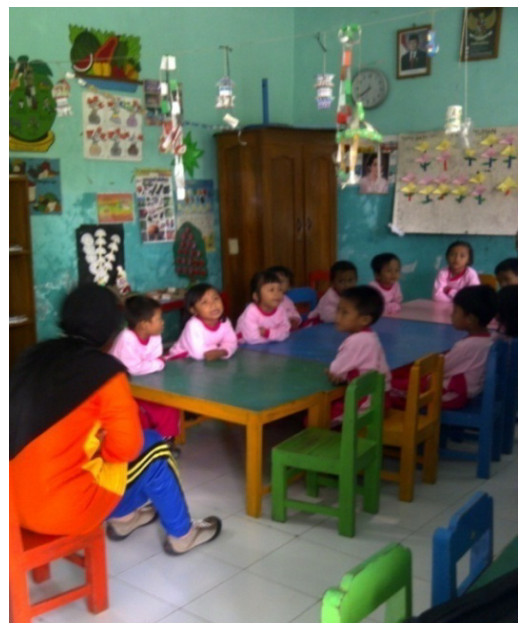

Gambar 1a

Guru sedang memberi perintah, instruksi, dan sejumlah larangan kepada anak-didik agar duduk manis diam terpaku dengan meletakkan tangan di atas meja dalam keadaan dilipat.

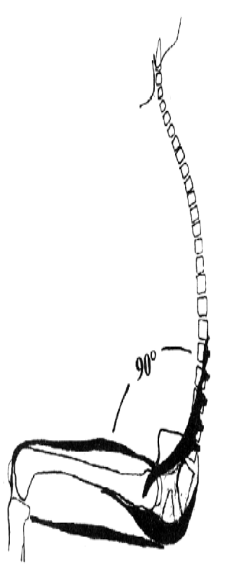

Gambar 1 b.

Tulang belakang anak menegang (peradangan batang otak/ sumsum tulang belakang) ketika duduk lebih lama. Tulang belakang anak tidak atau belum didesain untuk duduk dalam jangka waktu lama karena dapat merusak jiwa dan badan (Eric Jensen 2010: 96)

Gambar 1a dan $1 \mathrm{~b}$ di atas menjelaskan bahwa guru sedang memberikan instruksi agar anak duduk diam terpaku dengan melipat tangan di atas meja. Padahal, dalam neurosains, anak usia dini belum "didesain" untuk posisi tersebut (Clark 2017). Bagi anak, duduk adalah kerja keras yang menimbulkan kelelahan badan, menurunkan konsentrasi, meningkatkan kegelisahan (cemas), dan berpotensi menimbulkan masalah pada kedisiplinan (Eric Jensen, 2010: 96). Duduk dalam waktu yang lama tanpa jeda menjadikan tulang belakang meradang, tubuh lelah dan pernapasan menyempit. Sedangkan Guru robotik berpandangan bahwa anak yang baik adalah anak yang selalu taat dan patuh terhadap perintah guru, termasuk harus duduk manis diam terpaku melipat tangan di atas meja dalam jangka waktu yang lebih lama. 


\section{b. Anak-anak robotik; obyek pembelajaran}

Anak-anak robotik adalah anak-anak yang dijadikan diam membisu oleh gurunya sehingga ia hanya akan "bergerak" sesuai perintah dan instruksi guru. Mereka tampak tekun, rajin, dan rutin mematuhi semua instruksi guru, namun semua itu dilakukan bukan karena anak tersebut respek dan nyaman dengan gurunya, melainkan karena rasa takut: takut gurunya marah, takut salah, takut dihukum, takut dianggap anak nakal, dan lain sebagainya (Erden 2016).

Anak-anak robotik, belajar ke lembaga PAUD juga lebih didorong oleh perintah bahkan paksaan, bukan atas keinginannya sendiri. Mereka tidak begitu memperedulikan apakah di sekolah dirinya lebih riang gembira atau sebaliknya. Anak-anak robotik mengesampingkan perasaannya sendiri demi "menyenangkan" dan mematuhi perintah orang tua atau gurunya. Dengan demikian, anakanak robotik ke sekolah bukan untuk dirinya, namun untuk orang tua dan gurunya.

\section{c. Materi pembelajaran robotik}

Materi pembelajaran robotik adalah materi pelajaran yang oleh guru dipandang baik sehingga wajib dikuasai anak. Akan tetapi, anak itu sendiri tidak merasa membutuhkan materi tersebut bahkan meskipun telah dipelajari, anak tidak menangkap makna yang berarti dalam hidupnya. Materi pembelajaran robotik bersifat anti realitas, bahkan terkesan utopis. Anak-anak dipaksa mempelajari materi tertentu meskipun mereka menjadi semakin menderita di sekolah.

Dalam konteks PAUD berciri khas Islam, mereka mengajarkan membaca huruf hija'iyah melalui buku Iqra' dengan giat. Anak dipandang "berdosa" jika tidak bisa membaca tulisan hija'iyah (Yunanda et al. 2015). Bahkan, beberapa guru agama berpandangan bahwa membaca Arab lebih penting daripada calistung. Seringkali guru robotik menakut-nakuti anak bahwa anak yang tidak bisa membaca huruf hija'iyah atau tulisan Arab (berbahasa Arab), kelak di akhirat tidak akan bisa menjawab pertanyaan malaikat (Munkar dan Nakir), sehingga masuk neraka.

\section{d. Strategi Pembelajaran Robotik; Mekanik}

Strategi pembelajaran pada PAUD robotik adalah strategi pembelajaran yang mekanistik, atau metode pembelajaran yang 
monoton (ajeg). Jika dianalisis karakteristik guru dan anak-anak robotik sebagaimana dikemukakan di atas, dapat dilihat dengan jelas bahwa pola pembelajaran robotik bersifat satu arah (guru-anak). Konsekuensinya, strategi pembelajaran bersifat indoktrinatif, bukan transformatif, dan jauh dari kata trans-internalistik.

Dalam konteks PAUD berciri khas Islam, termasuk TK ABA, TK IT, dan RA, strategi pembelajaran robotik bercorak doktriner teologis. Anak ditunjukkan bahwa ini dosa, itu pahala; ini neraka, itu surga; ini benar, itu salah; dan seterusnya. Strategi ini tidak membuka peluang bagi anak untuk memilih opsi lain secara kreatif selain dua jalur itu, yang pada ujungnya anak dipaksa memilih salah satunya.

\section{e. Evaluasi pembelajaran labelistik}

Ciri utama model evaluasi dalam PAUD robotik adalah pelabelan atau labelistik. Meskipun secara dokumentatifadmisnistratif guru-guru robotik ini menggunakan teknik skala bintang satu $\left(* / 1^{*}\right)$ sampai empat $\left(* * * / 4^{*}\right)$, namun dalam praktiknya, ia sering mengeluarkan statemen-statemen tertentu (label) untuk menilai anak didiknya (Abramov and Russian 2017). Dengan kata lain, secara lahiriah ia melakukan evaluasi memenuhi standar administrasi-dokumentatif, namun secara batiniah (evaluasi terbatinkan), ia menjustifikasi anak didiknya dengan label-label tertentu. Bukti mengenai hal ini dapat diamati pada gambar 2 yang menunjukkan bahwa dalam reaksi spontan, ketika anak didik melanggar aturan (bicara sendiri ketika guru menjelaskan), secara refleks, guru tersebut langsung mengatakan, "Andre, jangan nakal!”.

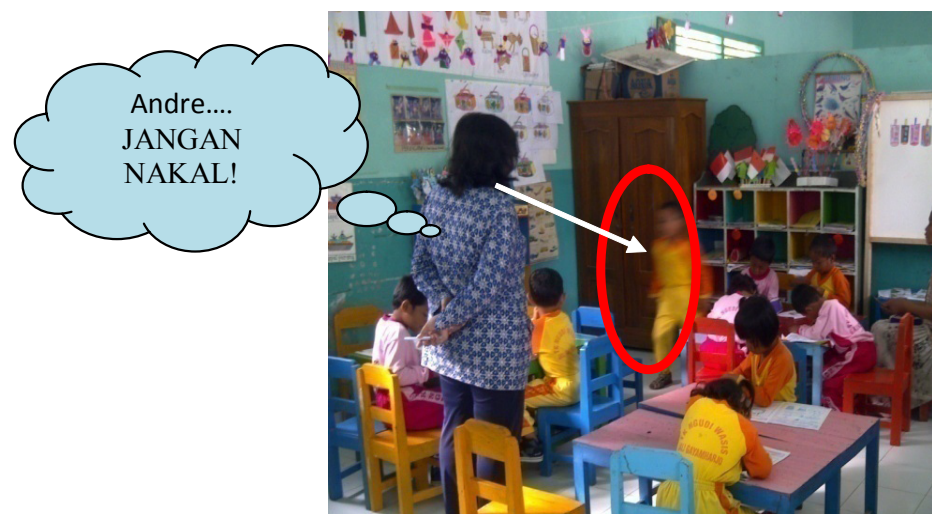

Gambar 2. 
Guru robotik melakukan labelling secara reflek terhadap anak didik yang tidak menuruti instruksi atau perintahnya dengan kata "nakal."

Model evaluasi labelling di PAUD robotik tersebut akan semakin jelas ketika sejak awal peneliti memasuki PAUD-PAUD di pelosok pedesaan. Dengan demikian, sebelum melakukan evaluasi pembelajaran, guru-guru robotik telah mempunyai label negatif tentang anak didik mereka. Hal ini menunjukkan bahwa model evaluasi labelling berjalan secara batiniah di hampir semua lembaga PAUD robotik. Bila PAUD robotik ini ditabulasikan secara terperinci, akan tampak sebagai berikut.

Tabel 1. Ciri-ciri PAUD Robotik

\begin{tabular}{|c|c|}
\hline Aspek & Ciri-ciri \\
\hline Konsep dasar & $\begin{array}{l}\text { PAUD robotik adalah PAUD yang beresiko merusak otak } \\
\text { anak, karena terlalu banyak instruksi, perintah, larangan dan } \\
\text { hukuman yang membuat suasana kelas menjadi mencekam } \\
\text { sehingga mematikan kreatifitas otak anak. }\end{array}$ \\
\hline Guru & $\begin{array}{l}\text { Guru robotikadalah diktatorkelas yang bersikap mekanistik, } \\
\text { otoritatif, dan indoktrinatif. }\end{array}$ \\
\hline Anak didik & $\begin{array}{l}\text { Anak didik di PAUD robotik adalah anak-anak yang } \\
\text { dijadikan diam membisu oleh gurunya, sehingga ia hanya } \\
\text { akan bergerak sesuai perintah dan instruksi guru. Mereka } \\
\text { belajar bukan karena ingin pintar, melainkan sekadar } \\
\text { mematuhi orangtua dan mentaati instruksiguru, di samping } \\
\text { paksaan dari keduanya. }\end{array}$ \\
\hline $\begin{array}{l}\text { M a t e r i / } \\
\text { kurikulum }\end{array}$ & $\begin{array}{l}\text { Materi pembelajaran robotik adalah materi pelajaran yang } \\
\text { oleh guru dipandang baik dan wajib dikuasai anak, namun } \\
\text { anak itu sendiri tidak merasa membutuhkan materi tersebut } \\
\text { bahkan meskipun telah dipelajari anak tidak menangkap } \\
\text { makna yang berarti dalam hidupnya. }\end{array}$ \\
\hline $\begin{array}{l}S \mathrm{t} r \text { a } \mathrm{t} \text { e } \mathrm{g} \mathrm{i} \\
\text { pembelajaran }\end{array}$ & $\begin{array}{l}\text { Strategi pembelajaran di PAUD robotik bersifat } \\
\text { mekanistik, perintah, nasihat, dan petuah disertai ancaman } \\
\text { dan hukuman. }\end{array}$ \\
\hline Evaluasi & $\begin{array}{l}\text { Secara lahiriah evaluasi di seluruh lembaga PAUD } \\
\text { (termasuk robotik) adalah mengikuti standar penilaian. } \\
\text { Namun secara batiniah evaluasi yang berlangsung di PAUD } \\
\text { robotik adalah pelabelan. }\end{array}$ \\
\hline
\end{tabular}




\section{PAUD Akademik}

Secara etimologi, kata "akademik" diartikan sebagai bersifat teoretis tanpa arti praktis secara langsung. Pada umumnya, istilah akademik selalu disinonimkan dengan Perguruan Tinggi (Nasional, 2012: 12). Pada jenjang inilah pembelajaran bersifat akademis, teoretis, bahkan seringkali filosofis. Berdasarkan maknanya secara etimologi ini, istilah "akademik" dapat diartikan sebagai pembelajaran yang bersifat konseptual (Manfra et al. 2017). Secara terminologi, istilah akademik dapat dimaknai sebagai pendidikan, keilmuan, logika matematika, sains, dan ilmu pengetahuan. Istilah "akademik" juga sering melekat pada kalimat "Tes Potensi Akademik" yang berarti uji logika. Berdasar pengertian terminologi ini, istilah "akademik" dapat diartikan sebagai pendidikan yang menekankan pada pengembangan kognitif.

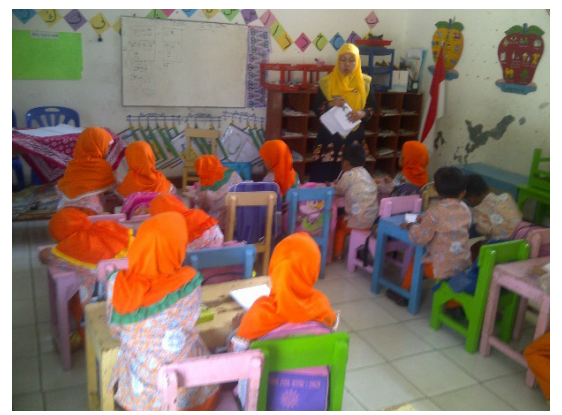

Gambar 3. Suasana kelas PAUD akademik

Berdasarkan pengertian akademik, baik secara etimologi maupun terminologi di atas, yang dimaksud dengan PAUD akademik Di sini adalah PAUD yang beresiko membonsai otak, karena potensi otak anak yang luar biasa hanya digunakan untuk mengembangkan kompetensi akademik (logika matematika, sains, bahasa,) melalui pembelajaran calistung. Dengan kata lain, Gambar 3 di atas mencerkan suasana kelas pada PAUD akademik yang mirip dengan sekolah dasar dan menengah. Selanjutnya, berikut ini dijelaskan ciriciri PAUD akademik secara sistematis.

\section{a. Guru PAUD akademik sebagai fasilitator}

Guru pada PAUD akademik cenderung berparadigma tunggal bahwa kecerdasan sebatas kemampuan di bidang akademik, yakni pengembangan logika, matematika, sains, bahasa dan baca-tulis (Juel 
1988). Di luar kompetensi akademik tersebut, dipandang sebagai kecerdasan sekunder. Ia berpandangan bahwa anak yang baik atau anak yang cerdas adalah anak yang mempunyai keunggulan di bidang akademik. Misalnya, guru lebih respek terhadap anak yang tulisannya lebih rapi daripada yang tulisannya nyeni (mirip lukisan, untuk tidak mengatakan seperti cakar ayam). Gambar 3a-b menunjukkan proses pembelajaran menulis anak TK kelas B 5 (usia 5,5 tahun).
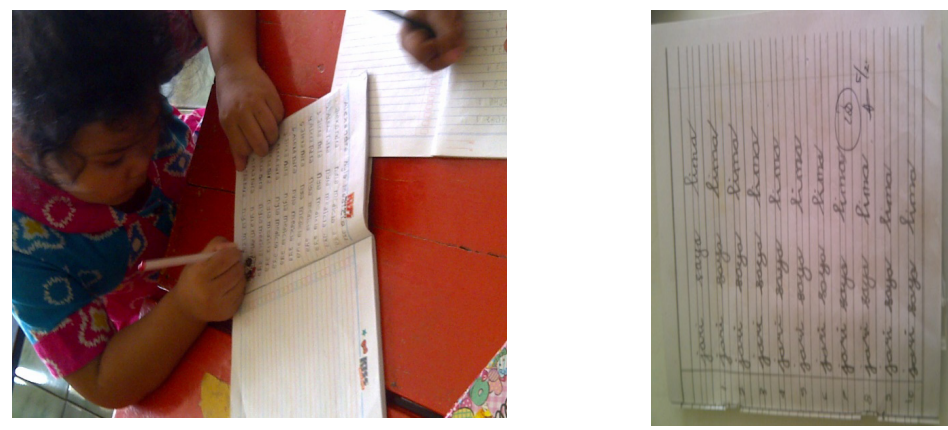

Gambar 3a-b. Tulisan anak akademik pada jenjang TK/RA.

Pada akhir kegiatan, guru-guru PAUD akademik selalu menanyakan selesai atau tidak tugas yang diberikan. Muara dari pertanyaan tersebut adalah sudah selesai menulis atau belum. Artinya, guru PAUD akademik selalu mencanangkan selesainya tugas-tugas pembelajaran yang bercorak akademis (Omar 2015). Guru akademik sebagai fasilitator tetap berorientasi agar anak didik mempunyai kompetensi akademis tinggi. Oleh karena itu, fasilitas yang diberikan sebatas menunjang kemampuan ini. Sedangkan aspek-aspek lain, seni, misalnya, kurang menjadi perhatian guru-guru PAUD akademik.

\section{b. Anak-anak akademik}

Anak-anak akademik adalah mereka yang lebih banyak melakukan kegiatan terkait tugas-tugas akademik, seperti belajar logika matematika, bahasa (membaca dan menulis), serta sains dan ilmu pengetahuan. Mereka mengejar "bintang", nilai, prestasi, dan penghargaan lainnya (Kara, Aydin, and Cagiltay 2013). Semuanya dilakukan bukan karena mereka memiliki keunggulan di bidang kecerdasan matematis logis sebagaimana disebutkan Gardner dalam Multiple Intelligences, namun lebih karena tuntutan orangtua dan guru. Lebih dari itu, anak-anak akademik oleh kedua orangtua mereka telah diikutkan les (pembelajaran tambahan di luar jam 
sekolah) untuk mengikuti baca-tulis dan berhitung. Kepala TK NtK Yogyakarta menyatakan:

"Sejak masuk TK, orangtua telah gelisah kemudian bertanya, 'apakah di TK ini (TK ABA Nitikan) ada pembelajaran calistung?' kemudian secara diam-diam mereka mengikutsertakan anak-anak pada program-program bimbingan baca tulis dan berhitung di luar sekolah." (Wawancara dengan Jamil, Kepala TK NtK pada Rabu, 12 Februari 2017).

Pernyataan kepala TK NtK di atas bukanlah satu-satunya, namun telah lazim terjadi di hampir semua TK/RA perkotaan. Calistung telah menjadi "hantu" bagi orangtua, seolah-olah jika anaknya lulus TK belum bisa calistung merupakan "aib" bagi keluarga.

Di lingkungan RA dan beberapa TK Islam, banyak orang tua yang mempunyai kegelisahan ganda, yakni takut jika lulus TK anaknya tidak bisa membaca abjad dan al-Qur'an. Oleh karena itu, di samping mengundang guru les membaca, mereka juga mengundang guru yang lain (ustadz/ ustadzah) untuk mengajarkan membaca al-Qur'an pada hari yang berbeda. Melalui metode Iqra', para ustadz/ ustadzah (guru les baca al-Qur'an) tersebut, dengan tekun mengajarkan anak-anak membaca huruf hijaiyah dengan sangat akademis.

\section{c. Materi pembelajaran akademik; satu tigkat di atas kemampuan anak}

Materi pembelajaran pada PAUD akademik sesuai dengan namanya, adalah kegiatan-kegiatan yang berorientasi pada pengembangan kompetensi akademik, seperti membaca perluman atau keaksaraan (Sulastri Yusro 2013: 342) berhitung atau mengenal angka dan bilangan (Ismatul Khasanah 2013: 14) bahasa, sains dan lain sebagainya (Aulina, 2012: 131). Bahkan, beberapa PAUD telah mengajarkan bahasa kedua atau bahasa asing (bilingual) (Garrity et al. 2018: 1), baik bahasa arab, inggris maupun mandarin. Semua kegiatan pada tiap-tiap tema pembelajaran, termasuk bermain (Anderson-McNamee, 2010: 2) syarat dengan muatan akademik. Seolah-olah kegiatan pembelajaran akan kehilangan maknanya tanpa capaian akademis tertentu. Gambar 4a-b-c menunjukkan buku ajar pada PAUD akademik. 

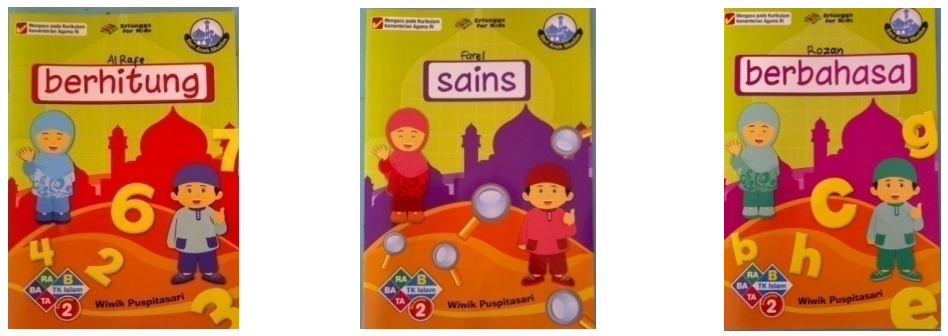

\section{Gambar 4a-b-c. Materi pembelajaran PAUD akademik}

Materi pembelajaran akademik pada dasarnya merupakan materi pembelajaran yang selalu satu tingkat lebih tinggi dari kemampuan anak sehingga anak akan belajar lebih keras untuk menyelesaikan tugas-tugasnya. Misalnya, materi pembelajaran SD sepuluh tahun yang lalu telah diajarkan pada TK hari ini. Sekadar contoh, dulu pembelajaran membaca dan menulis baru diajarkan pada jenjang sekolah dasar, namun sekarang materi itu telah lazim diajarkan di berbagai lembaga PAUD. Sebagai buktinya, peneliti menemukan buku karya M. Pordasi Siagian yang berjudul Nyanyian Anak-anak Sekolah Dasar di RA MsT Yogyakarta.

Dalam konteks PAUD Islam, seperti: RA, TK ABA, dan TK IT pembelajaran akademik ditambah dengan Baca Tulis Al-Qur'an (BTAQ), termasuk pembelajaran agama Islam berbasis multimedia (Suparni, 2016: 57). Bahkan, pembacaan doa dan beberapa hafalan lain telah menggunakan teknlogi digital. Lebih dari itu, saat ini mulai bermunculan lembaga PAUD yang menambahkan pembelajaran hafalan surat-surat pendek dalam Al-Qur'an (Zulfitria, 2016: 35) dengan alasan banyak SD/MI yang menargetkan hafal minimal 1 juz, yakni juz 30 (Fatah n.d., 2014: 335).

Secara teknis, ada yang mengajarkannya secara langsung dan ada yang sebatas hafalan. Gambar berikut ini adalah model pembelajaran BTAQ yang secara umum terjadi di berbagai lembaga PAUD. Bahkan, telah banyak dikembangkan metode pembelajaran BTAQ seperti pengenalan huruf hija'iyah digital (Lisna Zahrotun and Zaka Ricky, 2015: 75) hingga IQRO' berbasis android untuk anak (Yunanda et al., 2015: 78) 


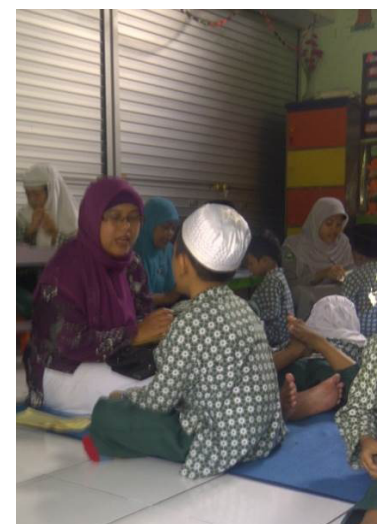

Gambar 5a.

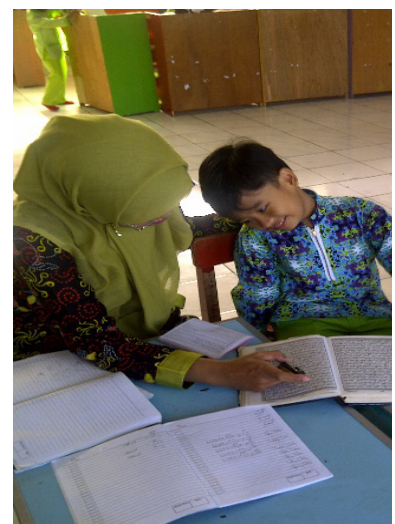

Gambar 5b.

Hafalan surat-surat pendek Pembelajaran Baca Tulis dalam juz'amma Alquran (BTAQ)

Gambar 5a menunjukkan pembelajaran yang sifatnya hafalan sangat mendominasi. Gambar $5 \mathrm{~b}$ menunjukkan bahwa materi pembelajaran Baca Tulis Al-Qur'an jauh lebih akademis daripada pembelajaran sains, matematika, dan berbahasa (Wekke 2015). Namun, atas nama ajaran agama, tidak ada yang berani melakukan kritik atas pola pembelajaran BTAQ tersebut. Bahkan, ada anggapan bahwa semakin lancar anak membaca al-Qur'an, maka semakin shalih/ shalihah anak tersebut; semakin banyak hafalan doa seharihari dan surat-surat pendek dalam al-Qur'an, mengindikasikan anak tersebut semakin baik.

\section{d. Strategi pembelajaran dinamik}

Secara umum, strategi pembelajaran yang digunakan di PAUD akademik relatif dinamik, seperti storytelling (Ma et al. 2012), story reading (Isbell et al. 2004), digital storytelling (Robin 2008) dan lain sebagainya. Strategi pembelajaran yang dominan di PAUD adakademik adalah bermain, sehingga terkenal dengan slogan, "bermain seraya belajar atau belajar seraya bermain) (Istiyani, 2013: 3-5). Beberapa PAUD menjadikan strategi ini sebagai slogan dalam pembelajaran. Namun demikian, dalam praktiknya bentuk konkret metode tersebut sulit dikenali. Artinya, satu kegiatan dapat dimaknai sebagai bermain, belajar, atau keduanya masih menjadi perdebatan. Jika parameter bermain adalah rasa senang (Anggani Sudono, 2006: 8) yang dialami anak, maka kegiatan yang sama dapat 
menimbulkan perasaan yang berbeda antara anak yang satu dengan yang lainnya. Gambar 6 menunjukkan permainan yang syarat dengan kompetensi akademik.

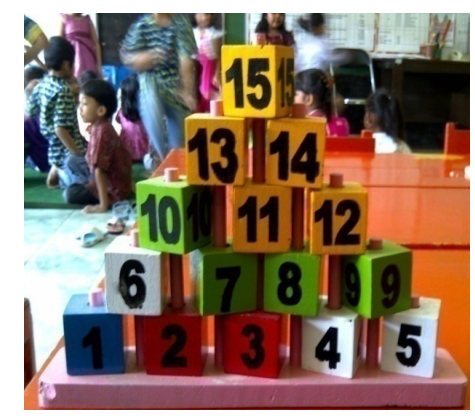

Gambar 6. Alat Permainan Edukatif (APE) Akademis, balok Pasak Bersusun

Gambar 6 mengindikasikan bahwa hampir semua bentuk permainan di lembaga PAUD telah bergeser dari edukatifke akademik. Muatan angka dan huruf yang kemudian anak diminta menyusunnya secara berurutan sehingga membentuk pola tertentu adalah salah satu indikasinya (Anderson-McNamee 2010). Bahkan saat ini telah banyak dikembangkan multimedia pembelajaran interkatif untuk pengenalan angka dan huruf bagi anak usia dini (Istiyani, 2013: 169). Hal ini mengundang tanda tanya, apakah sesungguhnya yang dimaksud dengan bermain dalam konteks pembelajaran anak usia dini? Telah banyak pakar yang membicarakan hal ini, namun semuanya belum berhadapan dengan realitas kontekstual sebagaimana dideskripsikan di atas.

\section{e. Penilaian berbasis tes dan kompetensi akademik}

Model evaluasi pembelajaran di lembaga PAUD akademik cenderung memberi penghargaan berlebihan terhadap prestasi akademik anak melalui tes dan non-tes(Tengah n.d., 2014: 211). Meskipun penghargaan tersebut sebatas tepuk tangan, "tepuk tangan untuk si A" atau pujian tertentu, "anak pintar", termasuk pemberian bintang $\left(^{*}\right)$, namun semuanya dimaksudkan untuk memacu anak agar mampu menyelesaikan tugas lebih baik agar semakin banyak penghargaan yang diperoleh.

Selanjutnya, evaluasi pembelajaran PAUD akademik selalu dicirikan dengan sejumlah tes yang sifatnya kognitif (Dundar and Ayvaz 2016). Tes di sini bukan berarti sejumlah soal yang harus 
dijawab pada lembar kerja seperti anak-anak sekolah, namun sejumlah pertanyaan post test setelah anak-anak melakukan kegiatan pembelajaran. Pada umumnya, model evaluasi ini berujung pada sistem ranking kelas yang menempatkan anak dengan skor tertinggi atau bintang terbanyak pada posisi teratas atau peringkat teratas. Sedangkan anak-anak dengan skor rendah dan hanya sedikit bintang ditempatkan pada posisi terendah.

\section{Tabel. 2 Cri-ciri PAUD Akademik}

\begin{tabular}{ll}
\hline \multicolumn{1}{c}{ Aspek } & \multicolumn{1}{c}{ Ciri-ciri } \\
\hline Konsep dasar & $\begin{array}{l}\text { PAUD akademikadalahPAUDyangberesiko membonsai } \\
\text { otak anak, karena potensi otak yang luasr biasany hanya } \\
\text { diorientasikan pada pengembangan akademik semata. }\end{array}$ \\
\hline Guru & $\begin{array}{l}\text { Fasilitator pengembangan kompetensi akademik, sepeti } \\
\text { membaca, menulis, berhitung, sain dan lain sebagainya. }\end{array}$ \\
\hline Anak didik & $\begin{array}{l}\text { Anak didik dipandang sebagai makhluk pembelajaran } \\
\text { yang bertugas mempelajari segala hal. }\end{array}$ \\
\hline Materi/ & $\begin{array}{l}\text { Materi pembelajaran didominasi pengembangan } \\
\text { kurikulum }\end{array}$ \\
& $\begin{array}{l}\text { kemampuan akademik seperti membaca, menulis, dan } \\
\text { berhitung. }\end{array}$ \\
\hline Strategi & $\begin{array}{l}\text { Secara teoretis "bermain seraya belajar, belajar seraya } \\
\text { pembelajaran } \\
\text { bermain", namun secara praktis, "bermain kemudian } \\
\text { belajar." }\end{array}$ \\
\hline Evaluasi & Prates-post tes, ujian tulis. \\
\hline
\end{tabular}

\section{PAUD Saintifik}

Secara etimologi, istilah saintifik berasal dari kata "sains" yang berarti ilmu sistematis yang dapat dibuktikan kebenarannya berdasarkan data-data empirik. Saintifik juga dapat dimaknai sebagai disiplin ilmu yang sifatnya ilmiah (Nasional, 2012: 495). Secara terminologi, istilah saintifik-termasuk neurosains-diartikan sebagai bentuk sains secara khusus, yakni ilmu pengetahuan yang disusun secara sistematis dan obyektif serta dapat diteliti kebenarannya (Achmad Maulana, 2004: 213). PAUD saintifik di sini didefinisikan sebagagi PAUD yang berorientasi pada pengembanan potensi otak anak didik secara holistik. 
PAUD saintifik merupakan kebalikan dari PAUD robotik sekaligus pengembangan dari PAUD saintifik. Jika PAUD robotik adalah PAUD yang beresiko merusak otak anak, sementara PAUD akademik merupakan PAUD yang beresiko membonsai otak anak, maka PAUD saintifik adalah PAUD yang berorientasi pada optimalisasi seluruh potensi otak anak. PAUD saintifik tidak lagi memperdebatkan pembelajaran calistung, bahkan telah mengarah pada pengembangan robotika pembelajaran anak usia dini yang mengintegrasikan seni, musik dan teknik, termasuk calistung di dalamnya, seperti yang dilakukan oleh Singapura (Sullivan and Bers, 2017: 1). Berikut ini dikemukakan ciri-ciri PAUD saintifik dilihat dari sisi guru, anak didik, materi pembelajaran, metode atau strategi, dan sistem evaluasi.

\section{a. Guru saintifik (Insinyur pembelajaran)}

Guru saintifik adalah insinyur pembelajaran yang aktif menyusun rancang bangun stimulasi edukatif bagi optimalisasi potensi otak. Ia merupakan guru transformatif atau pemimpin bagi anak-anak untuk melakukan peruhahan berpikir dan perspesi (Erden, 2016: 134). Guru saintifik sering menjai idola bagi anak-anak seperti bintang film (Schwarz-Franco, 2016: 994). Guru saintifik juga giat melakukan riset di dalam kelas (semacam penelitian tindakan kelas/PTK) (Suyadi, 2011: 15), membuat eksperimen pembelajaran(Yunanda et al., 2015: 25), dan haus akan inovasi pembelajaran serta aktif melakukan uji coba strategi-strategi pembelajaran terbarukan (Yunus, 2017: 48). Mereka juga motivator bagi anak untuk membangun rasa percaya diri secara kokoh (Rahman, 2013: 375). Termasuk dalam hal ini adalah perlakukan guru saintifik yang yang membedakan antara anak yang memiliki kecepatan belajar tinggi dan anak yang mengalami keterlambatan berpikir (Iigaya et al., 2017: 1-2).

Guru saintifik ketika mengajar bagaikan "memahat" otak anak-didiknya melalui berbagai treatment pembelajaran, termasuk memberi tantangan fisik yang dibedakan antara anak laki-laki dan perempaun karena keduanya memiliki karakteristik ketangkasan yang berbeda (Lander et al., 2017: 113). Inilah yang membedakan guru robotik dan akademik dengan guru saintifik. Jika guru robotik mengajar dengan menjadi diktator di dalam kelas, guru akademik 
mengajar dengan menjadi fasilitator, maka guru saintifik mengajar dengan menjadi katalisator.

\section{b. Anak-anak saintifik sebagai reaktor}

Anak-anak saintifik, bukan sekadar calon saintis sebagaimana anak-anak akademis yang dicetak untuk menjadi akademisi. Anak saintifik adalah anak yang tumbuh dan berkembang seluruh potensi otaknya secara optimal. Mereka tidak hanya memiliki kecerdasan tunggal secara intelektual, melainkan kecerdasan ganda (majemuk). Mereka berangkat ke sekolah (PAUD) bukan karena perintah dan paksaan orangtua seperti anak-anak robotik dan akademik, melainkan atas dorongan hasrat rasa ingin tahu yang berkobar dalam dirinya. Mereka berangkat ke sekolah (PAUD) seakan mengemban visi emosional, kebebasan berekspresi, berimajinasi, dan lain sebagainya. Hal ini menunjukkan bahwa kurikulum PAUD saintifik sangat mengedepankan pembelajran emosi (Clark, 2017: 2 ) atau dengan istilah lain pengembangan karakter. Jika anak-anak robot merasa dipenjara sepanjang proses pembelajaran di sekolah (PAUD), sedangkan anak-anak akademik merasa terbebani atas tugas-tugas akademik, maka anak-anak saintifik merasa ditantang untuk melakukan banyak kegiatan pembelajaran. Beberapa anak lebih memilih untuk berlama-lama di sekolah daripada harus segera pulang ke rumah.

\section{c. Materi pembelajaran saintifik}

Materi pembelajaran (kurikulum) pada PAUD saintifik adalah stimulasi edukatif, termasuk bermain (Alabekee, 2015: 2), khususnya kegiatan yang yang bermakna dalam kehidupan anak dan disesuaikan dengan kebutuhan masa depan anak (Mustaqim n.d., 2014: 1). Sebagaimana PAUD akademik yang mulai mengajarkan bahasa kedua (bilingual), (Garrity et al. 2018: 1) PAUD saintifik juga telah membekali anak dengan mengenalkan bahasa asing (Spies et al. 2017: 23). Materi pembelajaran dikemas secara empiris dan ditata sedemikiran rupa supaya mengundang decak kagum anak didik sehingga materi tersebut melekat dalam ingatan memori otaknya.

Sekadar contoh, seorang guru RA Masyithah mengemas materi pembelajaran "Rekreasi" dengan subtema "Perlengkapan Rekreasi, Nasi” secara empirik di sentra alam. Gambar 8a-b-c menunjukkan materi pembelajaran pada PAUD saintifik. 


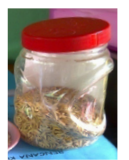

Gabah

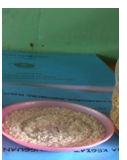

Beras

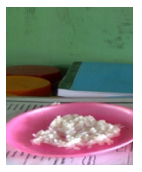

Nasi

Gambar 8. Materi pembelajaran saintifik

Pembelajaran anak usia dini dengan tema "Rekreasi” sub tema "Perlengkapan Rekreasi (nasi). Guru menjelaskan bahwa nasi berasal dari beras, beras berasal dari gabah, gabah berasal dari tanaman padi.

Gambar 8 merupakan contoh materi pembelajaran saintifik berupa bahan-bahan alam secara empirik yang dibawa masuk ke dalam kelas/sentra pembelajaran alam. Sentra-sentra pembelajaran yang lain akan berisi bahan-bahan ajar lainnya. Kurikulum PAUD santifik, dapat dimodifikasi oleh guru seaktu-waktu dalam penyusunan RPP yang lebih variatif, termasuk penerapan assesmen autentik (Garrity et al. 2018: 48).

\section{d. Strategi pembelajaran sebagai generator}

Sebagaimana telah disinggung di atas, bahwa strategi pembelajaran pada PAUD saintifik adalah rancang bangun stimulasi edukatif secara instrumentatif yang sifatnya variatif dan imajinatif (Colwyn Trevarthen, 2017: 1) serta dilakukan secara sistematis (Lubis et al., 2010: 665), bukan mekanistik dan dinamik seperti di PAUD robotik dan akademik. Di samping itu, strategi pembelajaran pada PAUD saintifik lebih banyak mengadopsi metode-metode pembelajaran quantum, seperti accelerated learning, quantum learning, active learning, multiple intelligences, coperative learning dan lain sebagainya (Tengah n.d., 2015: 279). Di Indonesia, strategi-strategi ini masih sebatas wawasan guru, belum menyentuh ranah praksis di ruang kelas pembelajaran.

Jika di atas disebutkan bahwa guru saintifik adalah katalisator, sementara anak-anak saintifik adalah reaktor, sedangkan materi pembelajaran sebagai stimulator, maka strategi pembelajaran saintifik adalah generator. Strategi pembelajaran quantum, termasuk multiple intelligences, bagaikan generator yang bekerja secara mikroskopis menghubungan neuron bermuatan informasi yang satu dengan neuron bermuatan informasi lainnya, kemudian bereaksi membentuk 
senyawa kimia baru yang kemudian dalam konteks pendidikan disebut ide kreatif dan imajinatif (Vygotsky 2004) .

\section{e. Evaluasi autentik, menggali keunikan potensi anak}

PAUD saintifik menggunakan model evaluasi autentik (authentic assesment). Asesmen autentik adalah proses evaluasi yang bermakna secara signifikan untuk mengukur kinerja, prestasi, motivasi, dan sikap pada ranah keterampilan dan pengetahuan sepanjang proses pembelajaran. Dalam konteks PAUD saintifik, asesmen autentik dimaksudkan untuk membuka rahasia potensi diri yang tersimpan dalam keunikan otaknya (Yunus, 2017: 48). PAUD saintifik, dengan multiple intelligences sebagai basis strategi pembelajaran, mustahil menggunakan model evaluasi kovensional yang hanya menggunakan kriteria tunggal secara terstandar. Penilaian autentik setidaknya dicirikan oleh empat indikasi, yakni (1) belajar tuntas, (2) proses berkesinambungan, (3) multikriteria dan (4) penggunaan teknik penilaian yang bervariasi. Belajar tuntas berarti anak tidak akan melakukan kegiatan lain sebelum kegiatan yang satu selesai (Yunus 2017). Menggunakan multikriteria berarti penilaian tidak sebatas ranah kognitif seperti pada PAUD akademik, tetapi juga mencakup afektif dan psikomotorik, di samping kecerdasan majemuk itu sendiri. Menggunakan teknik penilaian yang variatif berarti guru cermat memilih teknik evaluasi tertentu untuk menilai kegiatan tertentu pula.

Bila seluruh kajian di atas disimpulkan dalam bentuk tabel, maka akan tampak seperti tabel 4 berikut ini:

Tabel 4.

Diferensiasi Tipologis Varian PAUD Robotik, Akademik, dan Saintifik.

\begin{tabular}{|c|c|c|c|}
\hline $\begin{array}{l}\text { Komponen Inti } \\
\text { PAUD } \\
\end{array}$ & $\begin{array}{c}\text { PAUD } \\
\text { Robotik } \\
\end{array}$ & $\begin{array}{c}\text { PAUD } \\
\text { Akademik } \\
\end{array}$ & $\begin{array}{c}\text { PAUD } \\
\text { Saintifik } \\
\end{array}$ \\
\hline Konsep & $\begin{array}{l}\text { PAUD yang } \\
\text { beresiko merusak } \\
\text { otak anak }\end{array}$ & $\begin{array}{l}\text { PAUD yang } \\
\text { beresiko } \\
\text { "membonsai" } \\
\text { otak anak }\end{array}$ & $\begin{array}{l}\text { PAUD yang } \\
\text { berorientasi } \\
\text { pada optimaliasi } \\
\text { potensi otak anak. }\end{array}$ \\
\hline Guru & $\begin{array}{l}\text { Diktator kelas } \\
\text { administratif }\end{array}$ & $\begin{array}{l}\text { Fasilitator } \\
\text { pembelajaran } \\
\text { transformatif }\end{array}$ & $\begin{array}{l}\text { Katalisator } \\
\text { pembelajaran } \\
\text { Transinternalistik }\end{array}$ \\
\hline
\end{tabular}


Pendidikan Islam Anak Usia Dini Dalam Perspektif Neurosains...

\begin{tabular}{|c|c|c|c|}
\hline Anak didik & $\begin{array}{l}\text { Anak adalah } \\
\text { keturunan, } \\
\text { pewaris orangtua } \\
\text { dan guru }\end{array}$ & $\begin{array}{l}\text { Anak adalah } \\
\text { manusia tunas } \\
\text { muda generasi } \\
\text { bangsa }\end{array}$ & $\begin{array}{l}\text { Anak adalah } \\
\text { reakror } \\
\text { pembelajaran, } \\
\text { makhluk potensial }\end{array}$ \\
\hline Materi & $\begin{array}{l}\text { Kurikulum normatif } \\
\text { yangkadang annti } \\
\text { realitas }\end{array}$ & $\begin{array}{l}\text { Kurikulum } \\
\text { dominan akademik } \\
\text { (calistung) }\end{array}$ & $\begin{array}{l}\text { Kurikulum } \\
\text { kontekstual dan } \\
\text { saintifik } \\
\end{array}$ \\
\hline Metode & $\begin{array}{l}\text { Instruksi, } \\
\text { indoktrinasi, } \\
\text { perintah, dan } \\
\text { larangan }\end{array}$ & $\begin{array}{l}\text { Edukasi (bermain } \\
\text { seraya belajar) } \\
\text { bercorak nasehat } \\
\text { dan petuah }\end{array}$ & $\begin{array}{l}\text { Stimulasi } \\
\text { edukatif: strategi } \\
\text { dan imajinasi } \\
\text { kreatif }\end{array}$ \\
\hline Evaluasi & $\begin{array}{l}\text { Hafalan dan } \\
\text { pelabelan }\end{array}$ & Tes / unjuk kerja & $\begin{array}{l}\text { Authentic assesment } \\
\text { (menyingkap } \\
\text { potensi keunikan } \\
\text { otak anak } \\
\text { yang masih } \\
\text { tersembunyi) }\end{array}$ \\
\hline
\end{tabular}

\section{Simpulan}

Diferensiasi tipologi PAUD di atas terjadi pada tingkat mikroskopis atau soft-reality. Artinya, dalam sebuah lembaga atau institusi PAUD, di dalamnya memungkinkan untuk terjadi campuran ketiga tipe pembelajaran, baik robotik, akademik maupun saintifik. Sekadar contoh, TK N 1 SL (sebuah TK Negeri di Sleman), seluruh gurunya adalah saintifik, namun materi pembelajarannya sangat akademik. Berbeda dengan TK NtK (salah satu TK Swasta di Yogyakarta), materi pembelajarannya sangat saintifik, namun evaluasi pembelajarannya masih bercorak akademik. Lain lagi dengan PAUD FcS (salah satu PAUD swasta di yogyakarta), seluruh gurunya belumlah dapat disebut guru saintifik, namun strategi pembelajarannya sangat saintifik. Demikian seterusnya, sehingga tidak ada satu lembaga PAUD yang sepenuhnya robotik atau akademik maupun saintifik secara penuh.

Para orangtua dan masyarakat dapat mencermati kelima komponen PAUD (guru, anak didik, materi/ kurikulum, metode dan evaluasi) mana PAUD yang lebih dominan saintifiknya dari pada robotik dan akademik. Harus diakui, di Yogyakarta dan sebagian Jawa Tengah belum ada PAUD saintifik secara empurna, 
baik gurunya, anak didiknya, materinya, strategi pebelajarannya, dan ebaluasi maupun evaluasi pembelajarannya. Bagi para pengelola lembaga PAUD, pemetakkan yang menukik secara detail seperti ini dapat mengidentifikasi, aspek-aspek mana yang harus dipertahankan (sudah saintifik) dan aspek-aspek mana yang harus ditingkatkan (masih akademik) serta aspek-aspek mana yang harus dirubah secara total, karena masih robotik.

Bagi para pengelola PAUD pemetaan ini dapat menjadi bahan untuk membersihkan praktik-praktik pembelajaran robotik, memperbaiki pembelajaran yang masih akademik dan mengembangkan PAUD saintifik lebih variatif. Hal ini dapat dilakukan dengan menganalisis unsur-unsur kategori pada masing-masing tipologi PAUD (robotik, akademik, dan saintifik), baik gurunya, anak didiknya, materi pembelajarannya, strategi pembelajarannya, maupun evaluasi pembelajarannya. Berdasarkan penjelasan di atas, sudah seyogyanya PAUD robotik memetamorfosis diri menjadi PAUD saintifik, PAUD akademik menggeser diri ke arah PAUD saintifik dan PAUD saintifik terus mengembangkan diri lebih variatif. 


\section{DAFTAR PUSTAKA}

Abramov, Ruslan A, and Plekhanov Russian. 2017. "Evaluation of The Effeciveness of Russian Anti-Corruption State Policy in The Fieldof Education.” Journal of Legal, Ethical and Regulatory Issues 20(1): 1-10.

Achmad Maulana, Dkk. 2004. Kamus Ilmiah Populer Lengkap. Yogyakarta: Absolut. http://kin.perpusnas.go.id/ DisplayData.aspx?pId=31456\&pRegionCode=UNIGOR\&p ClientId $=136$.

Ali, Mahdi M. 2015. "Pembelajaran Pendidikan Agama Islam Bagi Anak Usia Dini Mahdi M. Ali Dinas Sosial (Panti Asuhan Nirmala) Kota Banda Aceh.” 1(July): 190-215.

Anderson-McNamee, Jona K. 2010. "The Importance of Play in Early Childhood Development." Family and Human Development: 1-3.

Anggani Sudono. 2006. Sumber Belajar Dan Alat Permainan. Jakarta: Grasindo. https://books.google.co.id/books/about/ Sumber_belajar_dan_alat_permainan.

Aulina, Choirun Nisak. 2012. "Kosakata Terhadap Kemampuan Membaca." 1(2): 131-43.

Chatib, Munif. 2009. Sekolahnya Manusia. Bandung: Kaifa. www. goodreads.com/book/show/6514168-sekolahnya-manusia.

___. 2012. Orangtuanya Manusia, Melejitkan Potensi Dan Kecerdasan Dengan Menghargai Fitrah Setiap Anak. Bandung: Kaifa. www.goodreads.com/ book/show/15779180orangtuanya-manusia.

Cicconi, Megan. 2014. "Vygotsky Meets Technology: A Reinvention of Collaboration in the Early Childhood Mathematics Classroom." Early Childhood Education Journal 42(1): 57-65.

Clark, Amy J. 2017. "Preschool Social Emotional Learning and Curriculum Design: The Changing System Changing System."

Colwyn Trevarthen, Jonathan Delafield-Butt. 2017. "Intersubjectivity in the Imagination and Feelings of the Infant: Implications for 
Education in the Early Years." http://www.springer.com/us/ book/9789811022746.

Committee on Early Childhood Mathematics. 2009. Mathematics Learning in Early Childhood: Paths Toward Excellence and Equity. eds. Taniesha A. Woods Christopher T. Cross and and Heidi Schweingruber. Washington, D.C.: The National Academies Press.

Dewantara, Ki Hajar. 1962. Karja Ki Hadjar Dewantara - Bagian Pertama: Pendidikan. Yogyakarta: MLPTS.

Dundar, Sefa, and Ulku Ayvaz. 2016. "From Cognitive to Educational Neuroscience." International Education Studies 9(9): 50. http://www.ccsenet.org/journal/index.php/ies/article/ view/56856.

Egbulefu Christian Alabekee Ph.D, Amaele Samuel Ph.D, Sunday D. Osaat Ph.D. 2015. "Effect Of Cooperative Learning Strategy On Students Learning Experience And Achievements In." International Journal of Education Learning and Development Vol.3, No.: 67-75.

Erden, Hale. 2016. "Pre-Service Teachers' Perceptions on Being a Teacher through a Metaphoric Perspective." 24(1): 134-47.

Eric Jensen. 2010. Art With the Brain in Mind. Alexandria,Virginia USA: Association for Supervision and Curriculum Development. http://www.ascd.org/publications/books/101011.aspx.

Fatah, Ahmad. "Dimensi Keberhasilan Pendidikan Islam Program Tahfidz Al-Qur' an A . Pendahuluan Salah Satu Aspek Kehidupan Umat Muslim Di Indonesia Yang Benar-Benar Memerlukan Pemikiran Dan Usaha Terus-Menerus Untuk Memperbaikinya , Adalah Bidang Pendidikan . (Ali , 1.” 9(2): 335-56.

Fischer, Kurt W. 2009. "Mind, Brain , and Education : Building a Scientifi c Groundwork for Learning and Teaching 1." Mind, Brain and Education 3(1): 3-16.

Freire, Paulo. 2008. Pendidikan Kaum Tertindas. Jakarta: Lp3es. https://www.demabuku.com/pendidikan-kaum-tertindas.

Garrity, Sarah, Cristian R. Aquino-Sterling, Charles Van Liew, and Ashley Day. 2018. "Beliefs about Bilingualism, Bilingual 
Education, and Dual Language Development of Early Childhood Preservice Teachers Raised in a Prop 227 Environment." International Journal of Bilingual Education and Bilingualism 21(2): 179-96.

George S. Morrison. 2012. Dasar-Dasar Pendidikan Anak Usia Dini (PAUD). Jakarta: Indeks.

Hook, Cayce J., and Martha J. Farah. 2013. "Neuroscience for Educators: What Are They Seeking, and What Are They Finding?" Neuroethics 6(2): 331-41.

Iigaya, Kiyohito, Yashar Ahmadian, Leo P Sugrue, and Greg S Corrado. 2017. "Learning Fast and Slow: Deviations from the Matching Law Can Reflect an Optimal Strategy under Uncertainty."

Isbell, Rebecca, Joseph Sobol, Liane Lindauer, and April Lowrance. 2004. "The Effects of Storytelling and Story Reading on the Oral Language Complexity and Story Comprehension of Young Children." Early Childhood Education Journal 32(3): 157-63. http://www.springerlink.com/openurl. asp?id=doi:10.1023/B:ECEJ.0000048967.94189.a3.

Ismatul Khasanah. 2013. "Pembelajaran Logika Matematika Anak Usia Dini (Usia 4 - 5 Tahun) Di Tk Ikal Bulog Jakarta Timur." Jurnal Penelitian PAUDIA, Volume 2 No. 1 Vol. 2., N.

Istiyani, Dwi. 2013. "Model Pembelajaran Membaca Menulis Menghitung." Jurnal Penelitian STAIN Pekalongan 10(1): 18.

Juel, Connie. 1988. "Learning to Read and Write: A Longitudinal Study of 54 Children from First through Fourth Grades." Journal of Educational Psychology 80(4): 437-47. http://doi. apa.org/getdoi.cfm?doi=10.1037/0022-0663.80.4.437.

Kara, Nuri, Cansu Cigdem Aydin, and Kursat Cagiltay. 2013. "Investigating the Activities of Children toward a Smart Storytelling Toy." Educational Technology and Society 16(1): 28-43.

Lander, Natalie J. et al. 2017. "Physical Education Teachers' Perspectives and Experiences When Teaching FMS to Early Adolescent Girls." Journal of Teaching in Physical Education 
36(1): 113-18. http://journals.humankinetics.com/ doi/10.1123/jtpe.2015-0201.

Lisna Zahrotun, and S. Zaka Ricky. 2015. "Media Pembelajaran Pengenalan Huruf Hijaiyah Untuk Anak Usia Dini 2-3 Tahun.” Telematika 12(2): 75-81.

Lubis, Maimun Aqsha et al. 2010. "Systematic Steps in Teaching and Learning Islamic Education in the Classroom." Procedia Social and Behavioral Sciences 7(October 2014): 665-70.

Ma, Kwan Liu et al. 2012. "Scientific Storytelling Using Visualization." IEEE Computer Graphics and Applications 32(1): 12-19.

Manfra, Louis et al. 2017. "Preschool Writing and Premathematics Predict Grade 3 Achievement for Low-Income, Ethnically Diverse Children." Journal of Educational Research 110(5): 52837. http://dx.doi.org/10.1080/00220671.2016.1145095.

Morrison, George S. 2007. Early childhood education today Early Childhood Education Today.

Mustaqim, Yunus. "Pengembangan Konsepsi Kurikulum Dalam Pendidikan Islam A . Pendahuluan Dewasa Ini , Kurikulum Sudah Menjadi Disiplin Ilmu Tersendiri Dan Telah Berkembang Cukup Signifikan , Baik Secara Teoritis Maupun Praktis . Dahulu , Kurikulum Dinamakan Kurikulum Tradi." 9(1): 1-24.

Nasional, Departeman Pendidikan. 2012. Tesaurus Alfabetis Bahasa Indonesia, Pusat Bahasa: Sinonim, Antonim, Hiponim, Dan Meronim. Bandung: Mizan.

Dirjen PAUD, Departemen Pendidikan, Direktorat Jenderal, And Manajemen Pendidikan Dasar Dan Menengah. 2009. "Surat Edaran Nomor: 1839/C.C2/TU/2009.” https:// drive.google. com/file/d/0B-1xIqIGe4j8TEtVX1FmYVlQdUk/view.

Nouri, Ali. 2016. "The Basic Principles of Research in Neuroeducation Studies." International Journal of Cognitive Research in Science, Engineering and Education 4(1): 59-66. http://scindeks.ceon. rs/Article.aspx?artid=2334-847X1601059N.

Omar, Ainon. 2015. "Storybook Read-Alouds to Enhance Students' Comprehension Skills in ESl Classrooms : A Case Study." Dinamika Ilmu 15(1): 99-113. 
Pasiak, Taufiq. 2009. Unlimited Potency of the Brain: Kenali Dan Manfaatkan Sepenuhnya Potensi Otak Anda Yang Tak Terbatas. Bandung: Mizan Bandung. http://mizan.com/index. php?fuseaction=buku_full\&id=2629.

_-_ 2016. "Tuhan Dalam Otak Manusia: Mewujudkan Kesehatan Spiritual Berdasarkan Neurosains.” In Mizan, Bandung.

Prasekolah, Anak-anak, and Siti Zulaikhah. "Urgensi Pembinaan Akhlak Bagi A . Pendahuluan Era Globalisasi Ditandai Dengan Kemajuan Di Bidang Teknologi Informasi . Kemajuan Di Bidang Tersebut Salah Satunya Internet, Dalam Hitungan Detik Informasi Dari Belahan Dunia Manapun Sangat Mudah Untuk Di Aks." 8(2): 355-72.

Rahman, Muzdalifah M. 2013. "Peran Orang Tua Dalam Membangun Kepercayaan Diri Pada Anak Usia Dini.” Jurnal Penelitian Pendidikan Islam 8(2): 374-88.

Reetu, Chandra. 2017. "Quality Early Childhood Care and Education in India : Initiatives , Practice , Challenges and Enablers." 11(1): 41-67.

Robin, Bernard R. 2008. "Digital Storytelling: A Powerful Technology Tool for the 21st Century Classroom." Theory into Practice 47(3): 220-28.

Schwarz-Franco, Orit. 2016. "Teachers in Film: Inspiration for Autonomous and Transformative Teaching or a Warning against It?" Universal Journal of Educational Research 4(5): 994-1002. http://www.hrpub.org/journals/article_info. php? aid $=3689$.

Spies, Tracy Griffin et al. 2017. "Beyond Professional Development: Factors Influencing Early Childhood Educators' Beliefs and Practices Working with Dual Language Learners." CATESOL Journal 29(1): 23-50. http://proxy.library.nyu.edu/ login?url=http://search.ebscohost.com/login.aspx?direct=tr $\mathrm{ue} \& \mathrm{db}=$ eric $\& A N=\mathrm{EJ} 1144338 \&$ site $=$ eds-live .

Stys, Yvonne, and Shelley L. Brown. 2013. "A Review of the Emotional Intelligence Literature and Implications for 
Corrections." Journal of Chemical Information and Modeling 53(9): 1689- 99.

Sulastri Yusro. 2013. "Pembelajaran Keaksaraan Untuk ANak Usia DIni." : 1-7.

Sullivan, Amanda, and Marina Umaschi Bers. 2017. "Dancing Robots: Integrating Art, Music, and Robotics in Singapore's Early Childhood Centers." International Journal of Technology and Design Education: 1-22.

Suparni. 2016. "Metode Pembelajaran Membaca Doa Berbasis Multimedia Untuk Anak Usia Dini." 2(1): 1-8. http:// ejournal.bsi.ac.id/ejurnal/index.php/ijse/article/view/668.

Suyadi. 2011. Panduan Guru Profesional, PTK, Dan PTS. Yogyakarta: Andi Ofset. https://www.tokopedia.com/dvbookstore/ptkdan-pts-suyad.

___ 2016. Teori Pembelajaran Anak Usia Dini Dalam Kajian Neurosains. Bandung: Remaja Rosdakarya. http://www. bukukita.com/Orang-Tua-dan-Keluarga/Psikologi-\&Pendidikan-Anak/129444-Teori-Pembelajaran-Anak-usiaDini-Dalam-Kajian-Neurosains.html.

Suyadi dan Maulidya Ulfa. 2013. Konsep Dasar PAUD. Bandung: Remaja Rosdakarya. https://www.tokopedia.com/bukukita/ konsep-dasar-paud-oleh-suyadi-dan-maulidya.

Tengah, Jawa. "Evaluasi Hasil Belajar Pendidikan Agama Islam (PAI) Kadang Digunakan Secara Bergantian, Namun Sebagian Besar Pengguna Membuat Perbedaan Di Antara Empat Istilah Tersebut . Penilaian Dan Evaluasi Lebih Bersifat Komprehensif Yang Meliputi Pengukuran, Sed." 9(2): 211- 36.

___..Pembelajaran Melalui Brain Based Learning Dalam Pendidikan Anak Usia Dini A . Pendahuluan Belajar Adalah Suatu Proses Yang Kompleks Yang Terjadi Pada Semua Orang Dan Berlangsung Seumur Hidup , Sejak Dia Bayi Sampai Ke Liang Lahat ( Sardiman , $2001: 1$ ).” 10(2): 279-300.

Vygotsky, Lev Semenovich. 2004. "Imagination and Creativity in Childhood (English Translation)." Journal of Russian and east European Psychology 42(1): 7-97. 
Wekke, Ismail Suardi. 2015. "Arabic Teaching and Learning: A Model from Indonesian Muslim Minority." Procedia - Social and Behavioral Sciences 191: 286-90. http://linkinghub.elsevier. com/retrieve/pii/S1877042815024969.

Widyastuti, Ana. 2018. "Implementasi Program Parenting Tentang Stimulasi Membaca, Menulis, Berhitung Bagi Orang Tua Dan Guru Paud Limo Depok." : 66-71.

Yunanda, Nindya Debby et al. 2015. "Jurnal Momentum ISSN : 1693752X Rancang Bangun Aplikasi Pembelajaran Iqra Untuk Anak Usia Dini.” Rancang Bangun Aplikasi Pembelajaran Iqra Untuk Anak Usia Dini Berbasis Android 17(1).

Yunus, Faridah. 2017. "Changing Curriculum Practice in Early Childhood Education Setting: An Action Research to Enhance Authentic Assessment." 4(11): 48-61.

Zulfitria. 2016. "Pembelajaran Tahfidz Al-Quran Dalam Pendidikan Karakter Anak Usia Dini (PAUD).” Darul Ilmi Jurnal Ilmiah Pendidikan Islam Anak Usia Dini Volume 1 N: 35.

Jamil (Kepala TK), Wawancara Oleh Suyadi. TK Nitikan Yogyakarta, Rabu, 12 Februari 2017.

Mastiti (Kepala Sekolah) Wawancara Oleh Suyadi. RA Karangnangka Sleman Yogyakarta, Jum’at, 8 April 2017. 
